Table 3. Patient knowledge and attitudes, by type of medication

original papers

\begin{tabular}{|c|c|c|c|c|}
\hline Knowledge/attitude & $\begin{array}{l}\text { Oral antipsychotic } \\
(n=55) \\
n(\%)\end{array}$ & $\begin{array}{l}\text { Intramuscular depot } \\
\text { antipsychotic }(n=22) \\
n(\%)\end{array}$ & $\begin{array}{l}\text { Antidepressant } \\
(n=24) \\
n(\%)\end{array}$ & $\begin{array}{l}\text { Lithium } \\
(n=13) \\
n(\%)\end{array}$ \\
\hline Knowledge of the purpose of medications & $12(24)$ & $6(30)$ & $10(40)$ & $6(48)$ \\
\hline Knowledge of side-effects & $6(12)$ & $5(25)$ & $2(8)$ & $3(24)$ \\
\hline Remembered receiving explanation from staff & $8(16)$ & $3(15)$ & $6(24)$ & $1(8)$ \\
\hline
\end{tabular}

No statistically significant difference across the groups.

were not our main focus of interest. Is the sample representative of other long-term patients? Findings elsewhere suggest that it may be. In an American state hospital population, only $8.4 \%$ could correctly name at least one of their medications, its dose and intended effect (Geller, 1982). Olin and Olin (1975) found that only $8 \%$ of a state hospital population were fully informed concerning their voluntary admission.

There is evidence that psychiatric patients themselves wish for more information about medications (Macpherson et al, 1993, 1996), although we did not ask about this. Worries that increasing patients' knowledge would decrease their compliance have not been substantiated (Schnieden et al, 1991; Rogers et al, 1993).

Our findings raise difficult questions about current psychiatric practice. Are long-term psychiatric inpatients told enough about the risks and benefits of treatment? How, and to what extent, can the prevalence of informed consent be improved in this patient population? Are patients, especially voluntary ones, adequately informed of their rights, and are those rights adequately protected? Are there adverse effects from increasing informed consent? In the absence of conclusive research evidence, the psychiatric professions and all those concerned for patient welfare must debate these questions.

\section{References}

BRITISH MEDICAL ASSOCIATION \& ROYAL PHARMACEUTICAL SOCIETY OF GREAT BRITAIN (1998) British National

Formulary. London \& Wallingford: BMJ Books \& Pharmaceutical Press.

DEPARTMENTOFHEALTH \& THEWELSH OFFICE (1993) Mental Health Act 1983. Code of Practice. London: HMSO.

EASTWOOD, N. \& PUGH, R. (1997) Long-term medication in depot clinics and patients' rights: an issue for assertive outreach. Psychiatric Bulletin, 21, 273-275.

\section{GELLER, J. L. (1982) State hospital} patients and their medication - do they know what they take? American Journal of Psychiatry, 139, 611-615.

MACPHERSON, R., DOUBLE, D. B. \& ROWLANDS, P. R. (1993) Long-term psychiatric patients' understanding of neuroleptic medication. Hospital and Community Psychiatry, 44,71-73.

Sidaway v. Board of Governors of the Bethlem Royal and the Maudsley Hospital (1985) Weekly Law Reports, 493

*K. W. Brown Consultant Psychiatrist, N. Billcliff Senior House Officer, E. McCabe Staff Psychiatrist, Forth Valley Primary Care NHS Trust, Royal Scottish National Hospital, Larbert, Falkirk, Scotland FK5 4SD
- JERROM, B. \& HUGHES, A. (1996) A controlled study of education about drug treatment in schizophrenia. British Journal of Psychiatry, 168, 709-717.

OLIN, G. B. \& OLIN, H. S. (1975) Informed consent in voluntary mental hospital admission American Journal of Psychiatry, 132, 938-941.

ROGERS, A., PILGRIM, D. \& LACEY, R. (1993) Experiencing Psychiatry: Users' View of Services. London: Macmillan MIND Publications.

ROTH, L. H., MEISEL, A. \& LIDZ, C.W (1977) Tests of competency to consent to treatment. American Journal of Psychiatry, 134, 279-284.

SCHNIEDEN, V., MEALHAM, P. \& GREENBERG, M. (1991) Audit and action in relation to drug prescribing for psychiatric patients. Psychiatric Bulletin, 15, 85-86.

\title{
The environment psychiatric patients create for themselves: the varying perceptions of professional staff
}

\section{AIMS AND METHODS}

A pilot study was undertaken to investigate whether there was evidence that professional staffs' perception of a patient's environment were significantly altered by certain variables.

\section{RESULTS}

Gender and, to a lesser extent, age were found to be variables that significantly affect the perception of a patient's personal environment.

\section{CLINICAL IMPLICATIONS}

Psychiatrists and other mental health professionals should be aware that there may be significant differences between the way individual professionals perceive the same visual environment. Psychiatry may benefit from future links with environmental psychology research. 
From the mid-1960s a new field of psychological enquiry developed and it began to influence a number of other disciplines, particularly architecture (Chaney, 1973). The contemporary field of environmental psychology now includes the study of the transactions and interrelationships between people and their socio-physical surroundings (including man-made and natural environments) and their relation to the other social, environmental and biological sciences. Information and methodology from this field are now used in a variety of areas including cognitive mapping, disaster planning, crime reduction, decision heuristics, risk management and many aspects of architectural and environmental design. Cognitive mapping is the process by which we acquire, encode, store, retrieve and decode information about our spatial surroundings. Heuristics (in this context) are the mental short-cuts we use to make decisions based on our past experience and are cognitively efficient, but can be sources of bias and error in our decision-making.

A topic of continuing interest within the discipline of environmental psychology is the concept of place; how places develop and acquire meaning for people and how they relate to people's plans of action, their preferences, their emotional reactions and, ultimately, their psychological well-being.

Concern about the deleterious effects of the hospital environment on psychiatric patients was expressed nearly 30 years ago by Goffman (1961) and an awareness of the range effects of the environment on individuals with schizophrenia has been stressed by Gabb et al (1992). A recent survey of the quality of care in acute psychiatric wards has stressed the importance of a safe and pleasant environment (Sainsbury Centre for Mental Health, 1998). Not surprisingly, the architecture and environment of psychiatric hospitals has become the subject of significant study (St Clair, 1989; Gulak, 1991). The primary objective of good psychiatric ward design is to create a comfortable and therapeutic setting that promotes both interest and activity (Remen, 1991). A variety of methodologies to assess in-patient environments have been used, including participant observation (Christenfeld \& Haveliwala, 1978), anthropological perspectives (Devisch \& Vervaek, 1986) and the use of specifically developed standardised tools (Jorda-Moscardo \& Iborra, 1991). Allowing psychiatric patients some control over their own environment is likely to produce positive effects (Lacy, 1981) and colour has been shown to produce consistent changes in mood states (Stone \& English, 1998). Concepts from environmental psychology have been usefully integrated into psychotherapeutic work (Peled \& Schwartz, 1999). Specific environmental interventions involving décor and furnishings have been studied over a period of weeks by Baldwin (1985) and a period of months by Christenfeld et al (1989) with favourable results, including reduction in in-patient violence and seclusion rates.

Important judgements about environments in which the psychiatric patients live and are treated are, therefore, routinely made by professional staff. There has, however, been little, if any, research into how the environmental perception of professional staff might vary. A pilot study was, therefore, undertaken to investigate the evidence of significant staff-dependent variables influencing professional perception of patients' personal environments.

\section{Method}

A valid and reliable instrument based on semantic differentials, the Environmental Rating Scale (ERS) (Pedersen, 1978), was selected and adapted for the purpose of assessing a small internal space. The original instrument contained 20 items - bipolar adjectives separated on seven-point scales. Five of the original items - unpleasantpleasant, uninteresting-interesting, depressing-stimulating, dirty - clean and irrational - rational - were selected for their relevance to assessing the small internal space of a bedroom. Each bipolar adjective was scored from one to seven, seven being the most favourable score. It was hypothesised that those professionals who had had years of contact with psychiatric patients might rate their environments less negatively than those more recently exposed to them and that women might rate environments more negatively than men. Prospective approval for the study was obtained from the local research ethics committee. All the patients in a medium secure psychiatric unit in the South-West of England were interviewed in January 1999. They were given an outline of the study and asked for permission to photograph their rooms, being told a photograph would be taken at some time over the next few weeks. Twenty-one out of 24 patients gave their written consent for photographs to be taken and three declined to take part in the study.

Photographs (transparencies) were taken of the bedrooms on a single day approximately 2 weeks after permission was obtained, using a wide-angle lens. The patients were given no additional warning that a photograph was to be taken. A form was then developed for scoring, with the adapted version of the ERS to rate the slides. The slides were projected onto a screen while groups of health care professionals (raters) were instructed to complete the rating form. Sixty seconds was allowed per slide for the purpose of rating and no rater required additional time. No conferring between raters was permitted. In all there were 48 raters -27 male and 21 female. Table 1 shows the representation of these rater groups, broken down by occupation.

Table 1. Breakdown by group

\begin{tabular}{lr} 
Occupation & $n$ \\
\hline Nurse & 8 \\
Consultant psychiatrist & 8 \\
Junior psychiatrist & 13 \\
Staff grade psychiatrist & 3 \\
Medical student & 14 \\
Other & 2 \\
Total & 48 \\
\hline
\end{tabular}

original papers 
Table 2. Mean (s.d.) room ratings made on each of the five dimensions, broken down by profession and gender of rater

original papers

Dimension on which room was rated

\begin{tabular}{|c|c|c|c|c|c|c|c|c|c|c|}
\hline \multirow{3}{*}{$\begin{array}{l}\text { Rater grouping by } \\
\text { profession or gender }\end{array}$} & \\
\hline & \multicolumn{2}{|c|}{ Unpleasant-pleasant } & \multicolumn{2}{|c|}{$\begin{array}{l}\text { Uninteresting- } \\
\text { interesting }\end{array}$} & \multicolumn{2}{|c|}{ Depressing-stimulating } & \multicolumn{2}{|c|}{ Dirty-clean } & \multicolumn{2}{|c|}{ Irrational-rational } \\
\hline & Mean & (s.d.) & Mean & (s.d.) & Mean & (s.d.) & Mean & (s.d.) & Mean & (s.d.) \\
\hline Nurse & 3.33 & $(1.55)$ & 3.30 & $(1.48)$ & 3.11 & $(1.40)$ & 4.01 & $(1.68)$ & 4.56 & $(1.85)$ \\
\hline $\begin{array}{l}\text { Consultant } \\
\text { psychiatrist }\end{array}$ & 3.51 & $(1.18)$ & 3.58 & $(1.33)$ & 3.28 & (1.39) & 3.80 & $(1.48)$ & 4.44 & (1.69) \\
\hline $\begin{array}{l}\text { Staff grade } \\
\text { psychiatrist }\end{array}$ & 3.25 & $(1.43)$ & 3.49 & $(1.60)$ & 3.37 & $(1.51)$ & 4.14 & $(1.32)$ & 4.21 & $(1.57)$ \\
\hline Medical student & 3.86 & $(1.53)$ & 3.38 & $(1.55)$ & 3.49 & $(1.51)$ & 4.21 & $(1.74)$ & 4.66 & $(1.69)$ \\
\hline Other & 3.67 & $(1.20)$ & 3.07 & $(1.33)$ & 3.17 & $(1.23)$ & 4.29 & $(1.07)$ & 4.86 & $(1.30)$ \\
\hline All women & 3.47 & $(1.52)$ & 3.31 & $(1.52)$ & 3.23 & $(1.47)$ & 4.12 & (1.57) & 4.55 & (1.59) \\
\hline
\end{tabular}

Data were analysed using Statistica 5.1 (Statsoft, 1997). Hypotheses that subjective ratings would vary according to profession or gender of the rater were examined using multiple univariate analyses of variance. The locations of significant differences were clarified where necessary using post hoc multiple comparisons (Tukey's honest significant difference test for unequal $n$; Spjotvoll and Stoline, 1973). The hypothesis that ratings would vary according to the age of the rater was examined by calculating separate correlations (Pearson's product moment) between ratings and age of rater for each of the dimensions along which ratings were made.

\section{Results}

Means and standard deviations of ratings made, broken down by professional group and gender, are presented in Table 2.

\section{Profession of rater}

Significant effects of rater profession were found on the unpleasant - pleasant dimension $(F(5,1002)=3.89$, $P<0.01)$ and the dirty-clean dimension $(F(5,1002)=2.71$, $P<0.05)$. Multiple comparisons to establish between which groups the differences lay revealed that the medical students rated rooms as being more pleasant than the nurses did, and the junior psychiatrists rated rooms as being cleaner than the consultant psychiatrists did.

\section{Gender of rater}

Significant effects of rater gender were found on the unpleasant-pleasant dimension $(F(1,1006)=10.64$, $P<0.01)$, the uninteresting-interesting dimension $(F(1,1006)=8.61, P<0.01)$ and the depressing-stimulating dimension $(F(1,1006)=7.55, P<0.01)$. In terms of all three qualities, men rated the rooms more positively than the women did.

\section{Age of rater}

A significant relationship between the age of rater and the ratings made was found on the unpleasant-pleasant dimension $(r=-0.083, P<0.01)$. In terms of this quality, increasing age of rater was associated with more negative ratings.

\section{Discussion}

The idea that there is a relationship between an individual's internal world and the external world they create has long been prevalent in psychiatry. This idea has been strengthened by concepts from child psychoanalysis (Winnicott, 1971). Dramatic and chaotic personal environments are seen with some types of psychiatric illness, especially the senile squalor syndrome (Shaw \& Shah, 1996), but also with other psychiatric disorders including schizophrenia. Visits to the domestic environment of patients are part of good community psychiatric care (Kates et al, 1991). Professional staff are routinely expected to assess both the appropriateness of particular living environments and how they might reflect an individual's mental state. A person's reaction to an environment is guided by his or her perception (Pedersen, 1978). Both cognitive and emotional dynamics shape an individual's response to a particular environment (Ritterfeld \& Cupchik, 1996).

Although the hypothesis about gender differences was supported, the hypothesis regarding age was not. Women rated the environments significantly more negatively than men did on three out of five dimensions, but increasing age was significantly associated with more negative ratings on arguably the most subjective, unpleasant-pleasant.

Earlier studies have reported some gender differences in both creating (Peichl, 1991) and rating environments (Ritterfeld \& Cupchik, 1996). The age effect was unexpected. It was thought that longer professional exposure to institutional and disordered environments would make individuals more tolerant of these; however, the reverse was true. The reasons for the differences are 
unclear. It is possible that the actual process of cognitive mapping in relation to visual environments may be primarily influenced by gender, or the differences may be related to heuristic principles, or combinations of both. However, it is important to appreciate that there may be significant differences in how individual professionals assess the same environment. In our view, the assessment of the personal living environment can influence a variety of important decisions involving the management of psychiatric patients; from precipitating admission to hospital, to the assessment of progress through rehabilitation and to eventual discharge and monitoring in the community. Psychiatry may benefit from further examination of developments in the field of environmental psychology to aid the treatment and management of patients.

\section{Acknowledgement}

The cost of purchasing film and developing the slides was covered by a grant from MrTim Hoult of Zeneca Pharmaceuticals.

\section{References}

BALDWIN, S. (1985) Effect of furniture rearrangement on the atmosphere of wards in a maximum security hospital. Hospital and Community Psychiatry, 56, 525-528

CHANEY, P. S. (1973) Décor reflects environmental psychology. Journal of the American Hospitals Association, 47, 60-66.

CHRISTENFELD, R. \& HAVELIWALA,Y. A (1978) A patient's views of placement facilities: a participant-observer study. American Journal of Psychiatry, 135 329-332.
Doors and thresholds: Jeddis approach to psychiatric disorders. Social Science and Medicine, 22, 541-551.

GABB, B. S., SPEICHLER, K. \& LODYL, K. (1992) Environmental design for individuals with schizophrenia: an assessment tool. Journal of Applied Rehabilitation Counselling, 23, $35-40$
GOFFMAN, E. (1961) Asylums: Essays on the Social Situations of Menta Patients and Other Inmates. NewYork: Doubleday.

GULAK, M. B. (1991) Architectural guidelines for state psychiatric hospitals. Hospital and Community Psychiatry, 42, 705-707.

JORDA-MOSCARDO, E. \& IBORRA, J. E. (1991) Study of alternative accommodation using the Hospital Hostel Practices Profile. Social Psychiatry and Social Epidemiology, 26, 151-156.

KATES, N., WEBB, S. \& LEPAGE, P. (1991) Therapy begins at home: the psychiatric house call. Canadian Journal of Psychiatry, 36, 673-676.

LACY, M. (1981) Creating a safe and supportive treatment environment. Hospital and Community Psychiatry, 32 , 44-47.

PEDERSEN, D. M. (1978) Dimensions of environmental perception. Multivariate Experimental Clinical Research, $\mathbf{3}$, 209-218

- (1986) Perception of interior designs. Perceptual and Motor Skills, 63, 671-676.

PEICHL, J. (1991) The outer and inner world physical configuration of the external setting arranged by the analyst. Zietschrift für

Psychosomatische Medizin und Psychoanalyse, 37, 128-145.

PELED, A. \& SCHWARTZ, H. (1999) Exploring the ideal home in psychotherapy: two case studies.
Journal of Environmental Psychology, 19. 87-94.

REMEN, S. (1991) Signs, symbols and the psychiatric environment. Psychiatric Hospital, 22, 113-118.

RITTERFELD, U. \& CUPCHIK, G. C. (1996) Perceptions of interior spaces. Journal of Environmental Psychology, 16, 349360.

SAINSBURY CENTRE FOR MENTAL HEALTH (1998) Acute Problems: A Survey of the Quality of Care in Acute Psychiatric Wards. London: Sainsbury Centre.

SPJOTVOLL, E. \& STOLINE, M. R. (1973) An extension of theT-method of multiple comparisons to include the cases of unequal sample size. The Journal of The American Statistical Association, 68, 976-978.

ST CLAIR, R. (1989) Psychiatric hospital design. Psychiatric Hospital, 18, 17-22.

SHAW, T. \& SHAH, A. (1996) Squalor syndrome and psychogeriatric admissions. International Psychogeriatrics, 8, 669-674.

STATSOFT (1997) Statistics forWindows Release 5.1. Tulsa, OK: Statsoft.

STONE, N. J. \& ENGLISH, A. J. (1998) Task type, posters and workspace colour on mood, satisfaction and performance. Journal of Environmental Psychology, 18, $175-185$.

WINNICOTT, D. W. (1971) Playing and Reality. Middlesex: Penguin Books.
*Ernest Gralton Forensic Psychiatrist in Development Disabilities, St Andrew's Hospital, Spring Hill, Cliftonville, Northampton NN1 5BE， Steve Pearson Specialist Registrar in Psychiatry, Hayter Unit, Torbay Hospital, Lawes Bridge, Newton Road, TorquayTQ27AA， Alastair Sutherland Staff Nurse, Martin Donovan Consultant Forensic Psychiatrist, Geraint Lewis Assistant Psychologist, Langdon Hospital, Dawlish, Devon EX7 ONR

\section{Service innovations: a service for the homeless with mental illness in Aberdeen}

\section{AIMS AND METHOD}

To evaluate the first 3 years of a newly developed service for the homeless mentally ill in Aberdeen. All 86 referrals to the service between 1996 and 1999 were reviewed.

\section{RESULTS}

The majority of referrals came from social care staff and self-referrals.
Half were diagnosed as having severe and enduring mental illness and of these one-quarter (11 cases) were engaged in long-term psychiatric care. A total of 744 in-patient days were required, only one admission was a compulsory detention.

\section{CLINICAL IMPLICATIONS}

It has proven possible to identify and engage with a number of homeless individuals who have untreated serious mental illness by setting up a small dedicated service that has close links with an established adult mental health team and which establishes close working relationships with colleagues in social care settings. original papers 